\title{
In defence of a university social work education
}

\section{Introduction}

The word 'defence' is used advisably, since there is good reason to believe that a University education for social workers in England (not Scotland, Wales, Northern Ireland or most of the 'developed' world) is under attack (Thoburn et al., 2016). And as someone who watched helplessly as probation was downgraded from requiring a highly-regarded graduate education to a two-year narrow specialist training, I know risk when I see it. So here is why I, along with the majority of social work educators in the UK and elsewhere in Europe (APSW, 2013; APSW and JUC/SWEC, 2014; APSW, 2016; Ferguson, 2016), opposed from the start the government move towards an expanded place for 'fast-track' specialist on-the-job training. In the light of experience, and some (limited) research and data on the shortened graduate training programmes, I still consider that, although there is a place for this entry route into professional social work, it should take up only a small part of the available funding and academic and practice teaching resource. Although some of my remarks are relevant to Step-Up (an earlier fast-track specialist trainee programme but still firmly linked in with University schools of social work), they refer especially to Frontline which is now almost entirely a 'stand-alone' training (Frontline, 2017). (There is still insufficient information for me to comment on Think Ahead, the Department of Health-funded and private equity-supported mental health fast-track trainee programme.)

My comments on 'mainstream' university courses refer to three-year undergraduate and two-year Masters programmes (or their part-time equivalents). In determining in 2002 that a three-year Honours degree in social work should be the minimum level qualification to be 
compliant with the European Directives on professional registration, the General Social Care Council (GSCC) concluded that post-graduates can complete the necessary curriculum in the two years because they have already been assessed at Honours degree level, and also have only limited breaks during the two-year course (GSCC, 2012). Each 'mainstream' programme has its own characteristics and specialisms within the broad curriculum but, in response to government requirements, the Regulator and university Quality Assurance Agency (QAA) mechanisms over the years, there is far more that unites them than separates them. Still, unless restricted to a particular geographical area, potential students can make choices between different approaches to the academic and practice learning on offer.

UK university-based social work education and training is admired across the world for its blend of rigorous scholarship with assessed experience in practice. But this is not to say that all 'mainstream' university programmes live up to their aspirations. Within programmes, some students have better experiences than others, and a small minority who complete the courses each year should not have done so. Student surveys and research reports identify the strengths and weaknesses of mainstream courses (see for example Manthorpe et al, 2006; Carpenter et al; 2012; Croisdale-Appleby, 2014; Narey, 2014). A small number of evaluations on the early cohorts of fast-track trainee schemes are now also available; Smith et al (2013), Baginski and Manthorpe (2014) and Hackett et al (2016) with respect to Stepup, and Maxwell et al (2016) with respect to Frontline, provide detailed evaluations which point to encouraging results in terms of the high-quality and well-rounded graduates and the satisfaction of most of them with the learning experience. 
However, the early short-course cohorts evaluated were still benefiting both from the 'haloeffect' of pioneer status and from the considerably more generous funding for recruitment and of the courses as well as the trainees. The methodology and the premises underpinning the Maxwell et al (2016) Frontline evaluation, but not its academic rigour, are contested, especially with respect to comparisons made with the (very small sample) of mainstream graduates, a proportion of whom will not have had direct experience of child and family work on which the evidence on competence is based (APSW/JUC-SWEC, 2014; Ferguson, 2016). Ferguson comments on the finding that Frontline graduates performed better on the simulated exercises than the mainstream students but also notes that the report 'is cautious about how the findings should be interpreted'. He notes the report's conclusion that 'an important question remains as to whether Frontline's superior performance in simulated interviewing is due to the distinctiveness of their students and selective recruitment or due to a training model that emphasises practice skills'. Reflecting on the as yet unanswered questions, some of which will be clearer when the planned follow-up evaluation is available, he concludes: 'We now need a robust debate about what social work education is for and the extent to which its future - in England at least - lies with 2-year MA and 3-year BA courses provided by universities or with the fast-track courses of 12-month Frontline or 14month Step-Up to Social Work programmes, or both'.

These are detailed quantitative and qualitative evaluations that are a rich source of information to which I can not attempt to do justice in this short article. Broadly speaking, the findings from the available evaluations about the different strengths and weaknesses of the fast-track specialist and more comprehensive mainstream programmes are in line with 
what follows. This article is a contribution to the debate called for by Ferguson, albeit focusing in the main on what mainstream university programmes can offer.

\section{Students not trainees}

The first point to make is that there is something special about learning as a university student rather than as an employee, trainee or apprentice contractually tied in with an agency that you may want to continue to work for as a qualified social worker. Some entrants to the profession prefer to remain with a current employer, and (the now rare) secondments and employment-based part-time university routes were devised to allow for these, with the Open University in particular assisting many to enter the profession in this way. But although much of the assessed practice is within the sponsoring agency, these are registered students and follow the same BA or MA curriculum, almost always including assessed learning in other agencies. Even so, the decline in numbers enrolling on full- or part-time mainstream university employment-based routes points to a preference for the flexibility of student status (Skills for Care, 2016).

The curricula for trainees and students may or may not be similar - the Health and Care Professions Council (HCPC) is tasked to seek to ensure that the basics are there - but the learning experience is qualitatively different. The student is more able to be adventurous, take risks if you like, with their own learning journey. Maybe they start out thinking that they would like to work with the elderly, but a first placement in mental health, or working with a mentally ill parent in a children's services team, results in a switch of future employment choice. Student status also frees up a student on placement, with the help of their tutor, their fellow students and usually their practice educator, to critique the practice or the service model they are experiencing, without worrying that this may cost them a 
future job in their home area. I say usually their practice educator, but anyone who has spent more than a few years as a university social work tutor will know that there can (happily infrequently) be student/ practice teacher clashes, or even, sad to say, abuse of power from which the student has to be rescued, with special efforts to ensure a better experience next time round. When the entrant to the profession is a trainee and-some 'observation' visits apart - most if not all their practice learning takes place within a single agency, the opportunity is lost to explore different models of service delivery or practice approaches, and a bad experience in their sponsoring agency can put them off a career in social work altogether. This problem is increased with the fast-track trainee programmes because time spent discussing and learning from other members of the student group using different approaches with different needs groups is curtailed by the more limited curriculum and shorter duration of the training.

Some ways of delivering traineeships seek to mitigate these problems, and many trainees will feel satisfied with their learning experience, and happy to stay put throughout, but most will have more limited opportunities to explore the relevant knowledge and practice approaches than those who have the greater freedom to experiment, to 'think outside the box', that comes with being a student. Although encouraged to continue their studies for a further year, those qualifying from the fast-track programmes are free to take their Postgraduate diplomas, register with HCPC, and apply for a social work post anywhere in England (the portability of these qualifications elsewhere in the UK and internationally is still uncertain: European Association of Schools of Social Work, 2015; McNicoll, 2017). 


\section{The process and values curriculum}

Before moving on to the knowledge, methods and skills curricula, the above comments raise the question of the process curriculum and the integration of professional and personal values. This is linked with allowing for different learning styles and teaching structures and methods. There is increasing scope for 'blended learning', that is different combinations of University and practice agency direct learning, web-based and distance learning. But for a profession for which community participation, inter-personal relationships and group interactions are so central, meetings with tutors and fellow students in different-sized groups in the university and on placement are an essential part of university as well as practice-based learning.

Learning about values permeates the academic and practice curriculum, from academic social science input to teasing out ethical dilemmas as they emerge in practice with individuals, families, groups and communities. I was a member of the training subcommittee of the Social Work Reform Board (DfE, 2010) and one of our papers - handed over as legacy to The College of Social Work (TCSW) - was entitled 'the process curriculum'. The two- or three-year programme of learning on a University course is planned as a group as well as an individual experience - a process through which the student is 'socialised' into the profession. This is achieved progressively via student-, tutor-, practitioner- and service user-led debates, especially around values. Developing an understanding of power relationships as they impact on the student and on those they are working with; taking the time to integrate apparently disparate theories into a coherent and practice-relevant whole; exploring group dynamics through membership of changing as well as stable groups - these all fall broadly within the 'process curriculum'. A shorter timeframe for these aspects of the 
process curriculum that contribute to students internalising confidence in their identities as professional social workers may in part explain the conclusion of the Frontline evaluators that, 'despite enjoying high ratings for practice quality, the Frontline trainees' rating of their own confidence in their abilities was lower than their mainstream counterparts' (Maxwell et al, 2016:10).

\section{The knowledge and skills curriculum in taught sequences and practice placements}

The social science, psycho-social and socio-legal foundations of social work knowledge One of the aspects of UK social work education much admired by colleagues in some other countries, including those with much longer qualifying programmes, is the integration of knowledge with practice learning from the very start. Although HCPC requirements stipulate the amount of time that must be spent in a practice setting, much learning about practice occurs within the university, and much knowledge input occurs on placement. This, of course, is the case for both 'trainee' and 'university student' programmes. That said, there are big differences in curriculum content, learning approaches and timing of the different elements. University programmes generally start with a broad introduction to the relevant social science knowledge and the context in which social work is practised, before progressing to the integration of this with more specific social work knowledge and theories for practice. The three recently-introduced trainee programmes are fast-track and specialist, and have a narrower curriculum, focused from the start on social work practice knowledge and skills, with less time given over to learning about and integrating broader social science knowledge and debates. The trainees are introduced during the six-week Summer school to issues of poverty and environmental pressures, and some social policy issues such as the 
complex workings of the health services, but these are likely to be 'one off' inputs by visiting speakers, most of whom are enthusiasts for the Frontline approach and practice model. But the pace of the teaching and learning to allow compliance with the minimum requirements for HCPC accreditation requires rapid move on, with little time for independent study, and the learning that can be more fully absorbed by reading in more depth around issues for a coursework assignment.

With the two- or three-year MA or BA programmes, there is more time for this early social science input to be absorbed and revisited in the context of increasing familiarity with the lives of the people needing services and the social work roles and tasks. There is some evidence in support of this point in the Maxwell et al (2016) evaluation in that, when commenting on the simulated cases, mainstream MA students out-performed Frontline students on the dimension of 'how students theoretically conceptualise substantive issues in the scenario and for their practice' (p.112).

Many and perhaps the majority of 'mainstream' students follow specialist options in their final year, and especially if complemented on placement, acquire the relevant legal and service-user and procedural knowledge for working with that group. But as noted by Croisdale-Appleby (2014) 'The initial qualification is the entry point to a profession in which learning should continue throughout the professional life of the individual' (p.71). It is not intended that 'generalist' social work students (any more than medical students) will have the detailed specialist knowledge allowing them to start from day one in a specialist area of practice. In that sense, they differ from those completing specialist qualifying courses. So for them the specialist learning during the Assessed and Supported Year in Employment (ASYE) 
is essential and much valued. They are, however, likely to be better equipped to take on new challenges and to transfer their knowledge from one setting or area of practice to another as their career progresses.

\section{Theories for understanding and theories for helping}

As is appropriate with mainstream university programmes that aim to qualify their graduates for practice in any area of social work, the emphasis is on generalist knowledge and skills that can be used flexibly and creatively across settings and needs groups. The term 'co-production' is these days more commonly used than 'partnership' but flexibility of approach is central to engaging with people who need services and colleagues from other professions to arrive at the most appropriate way of helping. I have found it helpful to avoid the term 'social work theory' or even 'theories' in the plural, and advise students to think in terms of 'theories for understanding' and 'theories for helping'.

In terms of the first, the qualified social worker needs a broad knowledge base on: aspects of environmental deprivation and stress that a client may have to contend with; how the public services work and interact with each other; the legislative framework for all aspects of social work; child and adult physical and mental health and development; and the possible causes and presentations of psychological and relationship difficulties. The discourse and terminology have changed over the years but the overarching approach to understanding the social work task remains remarkably unchanged - 'person in environment', 'psycho-social', 'ecological' or 'systems' approaches have been terms in fashion over the years. The last needs some comment - it is essential in social work to be aware of the systems surrounding the person in need, and those that impact on their own 
work setting, so a 'systems approach' to understanding permeates all qualifying programmes. But it is often mistakenly confused with a specific method such as 'systemic family therapy' which takes up a large part of the Frontline methods curriculum.

If beginning social workers are to be able to be creative and flexible in their response to clients with a wide range of difficulties, they also need a wide range of underpinning theories for helping. I have found it makes sense to students to distinguish between 'approaches', 'methods', 'skills' and 'techniques'. Looking first at approaches, in some form or other 'relationship-based' helping and the professional 'use of self' are the foundations of approaches to the social work task. Within this, the three broad approaches are derived from psychodynamic, behavioural and structural theories, with a more pragmatic 'eclectic' approach borrowing from each. 'Start where the client is' developed into a more defined 'task-centred casework' approach. 'Solution-focused' refers sometimes to a broad approach and sometimes to a specific method. According to the preferred approach he found in his observational research, David Howe (2009) concluded that most social workers could be grouped together in terms of their preferred approach as either 'fixers' or 'seekers after meaning'. In her wise memoir on a life in social work, Olive Stevenson argued for flexibility in the choice of theories to underpin helping methods. She expressed the hope that 'we have come far enough to accept that the ideological battles, fascinating and important though they are, should not, and need not, divert us from the sensible use of psychoanalytic theories and [...] an understanding of the importance of moving between inner and outer worlds as one important element in the development of skills in social work' and argued for 'a way of understanding people's behaviour which takes us 'a layer down'. This is not always necessary or appropriate: for example the widespread use of cognitive behavioural 
techniques in certain kinds of emotional disturbance is demonstrably valuable.'(Stevenson, 2013: 79-80). Each of these approaches will be covered, in more or less depth depending on the programme ethos and the placements of individual students, within a 'mainstream' qualifying programme, as, irrespective of worker preference, a partnership or 'coproduction' way of working may lead to one approach rather than another being the best wayforward.

Within these broad approaches, there are specific methods, some of them shared with other professions. 'Crisis intervention', 'task centred casework', 'systemic family therapy', 'functional family therapy', 'cognitive behavioural work', 'solution-focused casework', 'person-centred counselling', 'advocacy', 'debt counselling' and 'parent training' are all likely to have a mention as methods that may be in a social worker's tool kit, to be further developed as a career in social work progresses. One step down are the many techniques and tools such as 'active listening', 'welfare benefits screening', 'motivational interviewing' and 'scaling question', or the tools used as part of a behavioural, parent training or other 'bespoke' methods such as Signs of Safety. This is where the learning of students on different mainstream courses and within courses is likely to differ, especially depending on practice placements experienced.

But even bigger differences are to be found between mainstream and the fast-track specialist programmes with respect to the methods curriculum. The specialist courses tend to devote a larger share of the curriculum to methods and skills teaching, and indeed to concentrate on a narrow range of methods - in Frontline's case, systemic family therapy and motivational interviewing figure highly. (According to the evaluation of the first two cohorts, 
over half of the 20 Frontline recall days were given over to social learning theory or systemic family therapy based approaches; Maxwell et al, 2016.) On a 'mainstream' programme it is likely that a broader range of approaches and methods will be covered, and their appropriate use will be discussed in the context of analysis of practice issues that students meet during placements. There may be a series of lectures on different methods but whether or not a student actually learns the theory and practice of any specific method will depend on the ethos of the course and especially on the particular methods used by placement teams and practice educators, as well as on the needs of the adults and children they workwith.

The 'making sense and making use of research' curriculum

Finally, the learning experience on mainstream courses is permeated by an insistence that in seminars and in assignments undertaken as part of formative and summative assessment, and in their case analyses, students make appropriate use of the relevant research and other sources of relevant knowledge. 'Making sense of research' is a central component of teaching and for all Masters and some BA students this research literacy is consolidated by a dissertation. For Masters students in particular, the opportunity to delve in some depth into an issue that has particularly interested them is greatly valued, and for some, after a period in practice, brings them back into doctoral research and a career as a university educator/researcher.

In preparing this paper, I consulted six university faculty members who have responsibility for recruitment onto qualifying and doctoral programmes. To quote from a PhD admissions tutor: 'We do accept students onto the PhD programme who have a Masters in social work 
because we know that they will have learned a lot about research, and also have demonstrated their ability to study at Masters level. And with their practice experience, we can argue that they do not need a research Masters (generally considered to be a prerequisite for PhD study these days). People with the Frontline qualification but who haven't done a Masters dissertation are unlikely to be seen as eligible for PhD studies [without first completing a research Masters degree]'.

For the fast-track trainees, who gain their 'license to practice' after only 12-14 months, this opportunity is missing (it was there for the 18-month cohort 1 of Step-Up but then deleted to allow for qualification after 14 months). Some (it is not yet known how many) choose to complete the Masters degree and for Step-Up students this will most often be via a research-based dissertation. However, for Frontline students the Masters component is more likely to be via a leadership module or a specialist clinical module in family therapy or cognitive behavioural methods.

A social work educator commented: 'One thing that inspired me to do a PhD was being taught by research active staff in a research active environment. So is there likely to be a longer term impact [of a cut in mainstream social work MA numbers] in terms of recruiting future researchers - further eroding the knowledge base? So all the research relevant to people who use social work services will end up being done by non-social workers'.

\section{Does the student or trainee experience and length of study make a difference?}

From the research referred to above and my own experience, students completing a mainstream programme, as well as their first post employers, will often say that they still 
have much to learn and are well aware that a year of more detailed specialist practice and skills-based learning is essential. From his recent study of Frontline and mainstream graduates in their first year of practice, Little (personal communication) concurs, noting that although orthodox training generally takes longer, its alumni also tend to complain about speed. But at the point of qualification, they are likely to be more confident than fast-track trainees about the range of knowledge that they hold and where the gaps are. They may also be more confident in talking with colleagues from other professions about what is special about their own profession and not just about the methods and tools they are using - about their unique contribution as social workers to the team around the family or individual. They are less likely to use terms such as 'clinical practice' and more likely to frame their work as 'helping' than 'intervening', Although they will integrate into their practice the knowledge statements as they appear and change over time (as with the Knowledge and Skills statements for working in statutory children or adult settings), progression through their careers is more likely to be guided by the Professional Capabilities Framework (PCF) (DfE 2010) as they move on to more specialist or senior roles as advanced practitioners, managers, commissioners, educators or researchers. Some will settle into their profession in a statutory or third sector setting, creatively 'co-producing' a wide range of 'packages of care and support' and making use of a wide range of knowledge and skills before, in some cases, moving on to learn more specialist methods and skills, perhaps joining a multi-disciplinary team as a specialist (clinical) social worker, and others will retrain as therapists or psychologists. They are less likely to have the difficulties reported by some Frontline trainees that when they take up social work posts after 13 months they are unable to practise the specialist methods and skills they have majored in. 


\section{Concluding reflections}

I was invited to write this paper because of my 35 years as a university social work educator and researcher, as a former Vice Chair of GSCC when the protocols for accreditation of social work training courses were agreed, and as a member of the training sub-committee of the social work reform board. I have also been an external examiner on BA and MA programmes in 'Russell Group' and 'post-92' universities. That is what I have mainly written about and any comparative comments on Step-up and Frontline come from the still limited published evaluations. University programmes have been subject for many years to University QAA and Regulator visits, external examiner reports and professional, academic and practitioner debates, so I am clearer on my ground. The lack of detailed information on the websites of the fast-track programmes about curricula or the qualifications of those who deliver them means I am on shakier ground and I stand to be corrected. I have talked with Frontline and Step-up graduates who are in the main (as is usual with 'pioneers') proud spokespersons for their courses.

For reasons that are beyond the scope of this paper (but see for example Jones, 2016) the unevidenced message that mainstream courses are failing to produce child and family social workers or mental health social workers who can 'hit the ground running' has been used to justify a move to a specialist and narrower, technician style, training. I can see that there is a limited place for carefully selected graduates with relevant experience to undertake a shorter length university social work education, possibly via a funded traineeship. But assessing the relevance of a degree or prior experience can be tricky; it is not always straightforward to move from one profession to another and it cannot be assumed that the experienced nurse, counsellor, therapist, teacher or solicitor will need less time to learn to 
be a social worker than the literature graduate who has honed their empathy on an analysis of the characters in Dickens or Shakespeare. My experience is that sometimes there has to be un-learning before moving forward into a new profession. Having taught many in this position I can only recall one, who didn't stay long in social work, who said her MA course was toolong.

I totally understand why those who apply to these shorter and financially advantageous routes into social work do so and am aware that some who will make excellent social workers are entering the profession in this way. Some will say that they chose this model of training because it was what they really wanted. Most say they were attracted by the trainee salary (especially after incurring undergraduate debts) and not having to survive for another two years before earning a living wage.

However, there is no possibility of knowing the likely numbers who are both suitable for and will prefer a fast-track trainee route as long as there is such inequity in funding, both for the course providers and the students/trainees, between these and mainstream programmes. There are other models that can be looked at that encourage well-motivated graduates into social work and allow them to follow an inclusive social work curriculum. For over ten years the University of East Anglia (UEA) School of Social Work has jointly with neighbouring local authorities recruited graduates to start their course a year later after they have completed 12 months as a social work assistant. A small 'honorarium' is then provided while the student completes the MA in exchange for agreement to work with the authority on graduation. Cornwall County Council has a similar 'grow your own' scheme, seconding graduate and non-graduate staff members onto a university social work course after a year 
as trainee social workers. Although partnerships between university schools of social work and practice agencies have always been strong and have been further strengthened since the Reform Board, the additional DfE funding made available to the 15 Teaching Partnerships is likely to see the development of more such schemes to fit local circumstances. But this will only happen if adequate and sustainable funding is available to students, universities and the partner agencies providing placements.

The evaluations referred to above have not substantiated the view that - leaving aside the small numbers who fail to make the grade on social work as on other professional education programmes - a large majority of those qualifying on mainstream social work programmes will not become effective practitioners. Since the Social Work Reform Board changes have bedded down, employers are expressing greater satisfaction with the graduates they are able to recruit. Provided the basics are there, and the move into practice is supported and requisite new knowledge provided, the successful BA or MA student will settle confidently into social work and will be supported in making choices about the additional knowledge and skills they need. Agencies are on the whole good at providing local knowledge and skills training to fit workers for particular roles or updates on the law and practice guidance. However, the opportunity rarely arises again to explore all angles of key issues in greater depth, unless someone takes time out (and usually at considerable financial cost), to undertake a research degree. So that crucial time for integrating social science and professional social work knowledge that is skimped or not even touched on within a foreshortened and applied curriculum is unlikely to be available again. The risk is that some fast-track recruits will be highly skilled technicians but will struggle to be fully confident and adaptable professional social workers. 
So I retain my view that, as they enter one of the most complex and demanding professions, some of the potentially very able social workers tempted by financial necessity onto one of these short courses will have been 'sold short'. They are being let down by a government that appears to be unwilling to make even modest funds available for all those joining the profession to have the minimum two years of relevant higher education and training that all other countries consider to be a bare minimum. Like the doctors, psychologists, occupational therapists and physiotherapists they work with, social workers have a right to time to absorb and integrate complex and sometimes apparently contradictory knowledge and theories, explore the impact the work is having on them personally, examine their doubts and come out the other end feeling confident about their role as social workers and what thy have to offer.

But my argument, and I have sought to mount a defence and not to be defensive, is not only about the money and other resources going into these short courses, nor about the fasttrack programmes themselves. The diversion of funds from mainstream courses (DfE and DH funding for one fast-track trainee will pay for three MA students) has meant that other graduates and non-graduates who would have made excellent social workers have missed out as places on those courses are cut (already down from 5,620 course entrants in 2009-10 to around 4,000 in 2014-15) (Skills for Care, 2016). Other contributors to this special edition will explore further the impact of a more limited curriculum on the service provided to the increasing number of those whose need for a social work service is either caused or exacerbated by the experience of absolute as well as relative poverty and by appalling housing conditions (see also Bywaters et al, 2015). 
Finally, there are workforce planning questions to be urgently confronted at national and regional levels. In particular, potential social work recruits who are not already graduates or those wishing to work with the elderly or disabled adults will find it increasingly difficult to join the social work profession. The Education Select Committee (HoC, 2016) called for a full debate by all stakeholders on the respective place and appropriate balance between numbers on mainstream and fast-track programmes. The present direction of travel and DfE and DH funding decisions (which have not as yet been subject to the debate and scrutiny called for by the Education Committee) are already resulting in a decrease in social work undergraduates and post-graduates qualifying on mainstream university programmes, at a time when recruitment and retention of social workers is reaching crisis proportions.

\section{Implications of the research for policy and practice}

- Social work students on mainstream programmes and fast-track specialist trainees have qualitatively different learning experiences

- Choice of route into social work is distorted by the unequitable funding for students, universities and practiceeducators

- The growth in numbers and the proportion of specialist fast-track graduate entrants has occurred with insufficient discussion, involving all stakeholders, of the implications for the profession and for those who need social work services. 


\section{References}

Association of Professors of Social Work (2013) A Joint Statement on the Frontline Proposal byJUC/SWEC and APSW11 Feb 2013 http://www.apsw.org.uk/2013/02/a-joint-statementon-the-frontline-proposal-by-jucswec-and-apsw/ accessed 23.03.17 Association of Professors of Social Work (2014) Joint APSW and JUCSWEC statement on the evaluation of Frontline 22 Oct 2014

http://www.apsw.org.uk/2014/10/joint-apsw-and-jucswec-statement-on-the-evaluation-offrontline/ accessed 23.03.17 Association of Professors of Social Work (2016) Submission to Education Committee Inquiry into the Reform of Children's Social Care and Social Work Education in England http://www.apsw.org.uk/2016/01/reform-of-childrens-social-care-and-social-workeducation-in-england/accessed 22/03/2017

Association of Professors of Social Work and JUC-SWC (2014) Joint Statement on the Evaluation of Frontline 22 Oct 2014 http://www.apsw.org.uk/2014/10/joint-apsw-andjucswec-statement-on-the-evaluation-of-frontline/ accessed 2 May 2017 Baginsky, M. \& Teague, C. (2013) 'Speaking from experience: the views of the first cohort of trainees of Step Up to Social Work', London: Department for Education.

Baginsky, M. \& Manthorpe, J. (2014) 'The Views of Step Up to Social Work Trainees - Cohort 1 and Cohort 2', London: Department for Education.

Bywaters, P., Brady, G., Sparks, T., Bos, E., Bunting, L., Daniel, B., Featherstone, B., Morris, K., Scourfield, J. (2015) ‘Exploring inequities in child welfare and child protection services: explaining the "inverse intervention law", Child and Youth Services Review 57:98-105. Carpenter, J (2012) Newly Qualified Social Worker Programme: Final evaluation report (2008 to 2011). 
Croisdale-Appleby, D. (2014) Re-visioning social work education an independent review. London Department of Health.

Department for Education (2010) Building a safe and confident future: progress report from the social work reform board London: DfE https://www.gov.uk/government/publications/building-a-safe-and-confident-futureprogress-report-from-the-social-work-reform-board accessed 23.03.17 European Association of Schools of Social Work (2014) Statement regarding the development of 'Frontline' graduate social work course in the UK Ferguson, $\mathrm{H}(2016)$ 'Without university social work departments, the profession cannot survive' Community Care 6 April 2016.

Frontline (2017) Academic Programme http://www.thefrontline.org.uk/ourprogramme/frontline-programme-details/academic-programme accessed 23/03.17 General Social Care Council (2012) Regulating social work education (2001-12) London: GSCC.

Hackett, S., Smith, S., Stepanova, E., Venn, D,. Carpenter, J.,\& Patsios, D. (2016) Step Up to Social Work Longitudinal Evaluation. Durham: Durham University https://www.dur.ac.uk/resources/sass/research/SUSWInitialfindings21Mar2016.pdf accessed 23.03.17 House of Commons Education Committee (2016) Social work reform Third Report of Session 2016-17 Howe D (2009) A Brief Introduction to Social Work Theory. London: Palgrave Macmillan. Jones, R. (2016) Submission to the Education Committee Inquiry on Social Work Reform http://data.parliament.uk/WrittenEvidence/CommitteeEvidence.svc/EvidenceDocument/Ed ucation/Social\%20work\%20reform/written/28907.html accessed 23.03.17 
Little, M. (personal communication)

McNicoll (2017) 'Frontline graduates face restrictions on practising outside of England' http://www.communitycare.co.uk/2017/04/03/frontline-graduates-face-restrictionspractising-outside-england/accessed 6 May 2017 Manthorpe, J.; Moriarty, J.; Hussein, S.; Huxley, P.; Evans, S.; Orme, J.; Crisp, B.; Dutton, K.; Green Lister, Pam; Cavanagh, K.; MacIntyre, G.; Stevens, M.; Sharpe, E. (2005) The evaluation of the new social work degree qualification in England: wider perspectives. European Journal of Social Work, Vol. 8, No. 3, 08.2005, p. 343-346. Maxwell, N.; Jonathan Scourfield, Meng Le Zhang, Teresa de Villiers, Mark Hadfield, Paul Kinnersley, Liz Metcalf, Andy Pithouse and Sadia Tayyaba (2016) Independent evaluation of the Frontline Pilot Research report March 2016 London: DfE.

Narey, M. (2014) Making the education of social workers consistently effective: Report of Sir Martin Narey's independent review of the education of children's social workers. London: DfE.

Skills for Care (2016) Social Work Education in England: London, SfC.

Smith, R., McLenachan, J., Venn, L., Weich, H. \& Anthony, D. (2013). Step Up to Social Work Programme Evaluation 2012: The Regional Partnerships and Employers Perspectives.

London: Department for Education.

Stevenson, O. (2013) Reflections on a Life in Social Work: A Personal \& Professional Memoir. Buckingham: Hinton House.

Thoburn, J., Featherstone, B. and Morris, K. (2016) 'The future of social work in universities is under threat', Community Care 7 March. 


\section{Author biography}

June Thoburn CBE, LittD is an Emeritus Professor of Social Work at the University of East Anglia. She qualified as a social worker in 1963 and worked in Canada and England as a child and family social worker and generalist 'patch' social worker before moving into research and teaching. She has published widely on child and family policy and practice in international context, was Vice Chair of GSCC and an elected faculty member of The College of Social Work. 